\title{
THE PEDAGOGY OF 'COMING-OUT’: TEACHER IDENTITY IN A CRITICAL LITERACY COURSE
}

Navan N. Govender

Wits School of Education: University of the Witwatersrand

navan.govender@wits.ac.za

Accepted manuscript - pre-publication

\begin{abstract}
Coming out as lesbian, gay, bisexual, transgender, intersexed, queer or asexual is a highly contested issue. In an educational context there are arguments about the role of coming out to students and learners, yet it is still difficult to say decisively whether or not declaring one's identity is pedagogically necessary or effective. The decision to come out, or not to come out, relates to 'the closet' as an 'open secret', where the boundaries between identity and private/public spaces can be negotiated. Using arguments that see the closet as a fixed space associated with shame, fear and falsity, this article seeks to present the closet as a constructive space for identity formation and social negotiation. Such an understanding of the closet is related to how gender is marked and read in socio-cultural context. I then use these arguments about the closet to explore my own pedagogical decision not to come out in a critical literacy course for pre-service teachers. What emerged from my own 'open secret' are three conversations with students that brought into question my identity as gay, male, an English lecturer and an academic. A critical reflection of these conversations reveals how students read my identity during lectures, and how these readings initiated concerns about my gendered performance, and my investment in the field. Furthermore, my analysis also considers how my 'closeted' identity may have created the space for openly discussing students' perspectives on sex, gender and sexual diversity.
\end{abstract}

Key words: critical literacy, coming out, gender performance, teacher identity, the closet

\section{INTRODUCTION}

In 2015, photographer and global thinker, Robin Hammond from New Zealand began the Where Love is Illegal campaign. The campaign aims to document the experiences of lesbian, gay, bisexual, transgender and intersexed (LGBTI) people from 
around the world - particularly those living under oppressive regimes that use national policy to condemn and even incarcerate those who identify as LGBTI. Hammond uses social media platforms like Instagram and a blog page to collect and store photographs and stories of LGBTI experiences. Participants can submit their pictures (or a suitable picture that does not identify them) alongside their written stories to http://whereloveisillegal.com/ where it becomes publicly available.

The blog site contains hundreds of stories from countries around the world, across race, gender identity, sexual orientation and class status: From Uganda, Malaysia, and South Africa, to the United States and the United Kingdom. Each story is written by the participant, and is expressed in their own emotionally loaded ways. This blog illustrates the vast array of experiences of LGBTI people across contexts that still function within heterosexist frameworks. From overtly political frictions between state, religion and identity to everyday silences and marginalising interactions, these stories illustrate the complexity of negotiating one's identity in socio-cultural context especially when that identity does not fit social and institutional norms.

Throughout the blog there are stories that illustrate the kinds of experiences that the participants have as well as the oppressive conditions under which many LGBTI-identifying people live. A number of examples from South African participants aid in emphasising the persistence of heteronormativity and heterosexism evident in both institutional and everyday spaces. One example, and extract (see Figure 1), comes from a teacher in Russia and serves as an example experience of LGBTI teachers specifically.

Olga's story (Hammond 2015) reveals the complexities of having to negotiate one's teacher identity with a gendered or sexual identity. To what extent can teachers un-closet their sexual identities, and what function can the closet play in educational settings? 


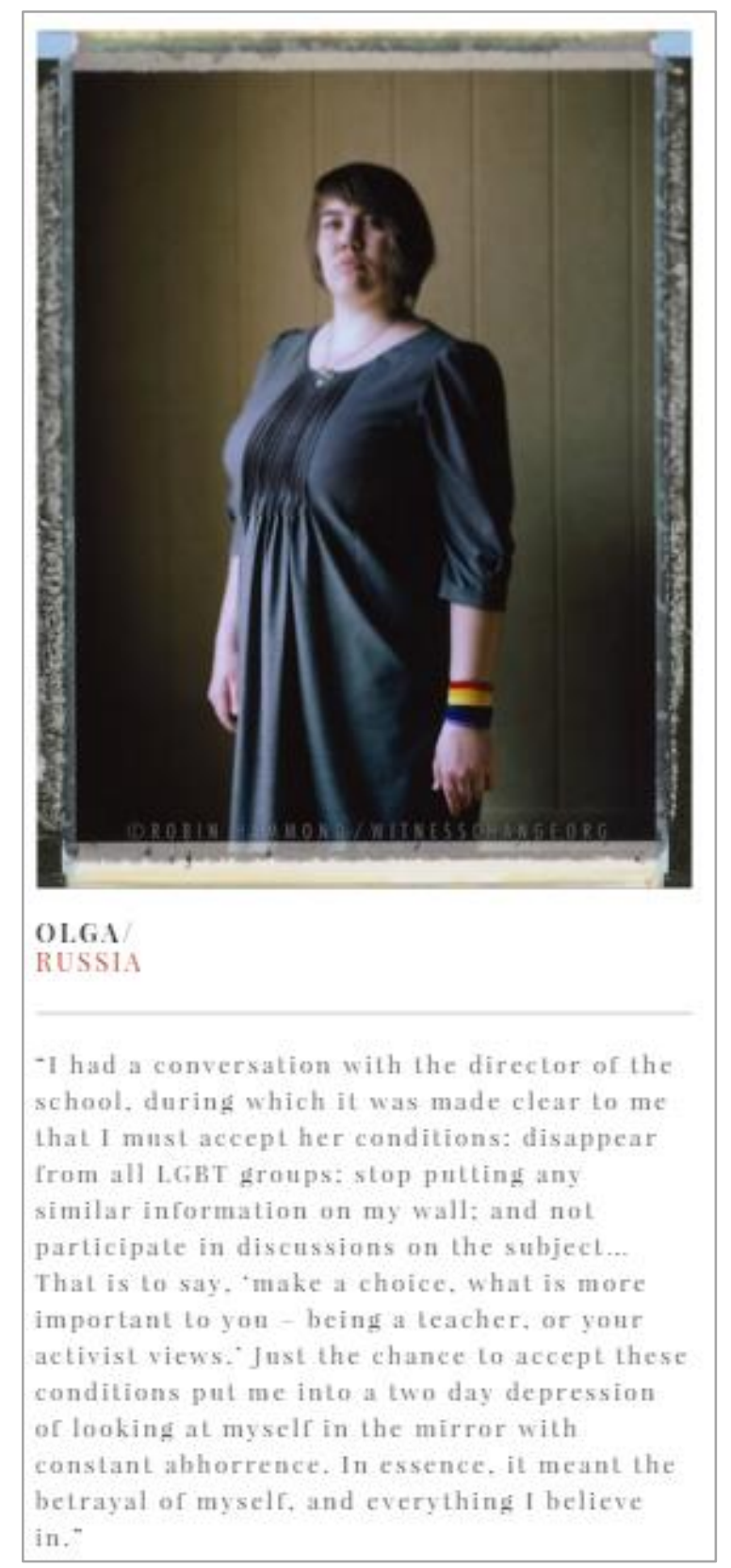

[Figure 1 - Excerpt from Olga's blog entry]

Olga's description of how her LGBTI-related identity was regulated at the school she worked for is indicative of the choices available to those who live non-conforming lives. In order for Olga to choose 'what is more important' (in Hammond 2015) resulted in significant emotional and psychological trauma, a consequence felt by many LGBTI people in South Africa (Luyt 2012; Reddy 2009; Bhana 2012).

The issue of coming out is thus a highly contested one. In the educational environment, it is particularly difficult to say decisively whether or not identifying one's 
sexual orientation should be a requirement for teachers and learners, especially because there are questions about who should come out and why.

In this article, I reflect on the concept of the closet in relation to teacher identity. I consider how my pedagogical decision to remain silent about my own sexual identity during a higher education critical literacy course with pre-service teachers studying a Bachelor of Education (B.Ed.) gave rise to three unprompted but significant conversations with students. In each conversation, students engaged in reading my identity. In each reading, students seemed to transgress the boundaries of public/private spaces (Miller 1988). But, these questions and comments have had a real and interesting effect on my own understanding of teacher identity, the role of coming out in classroom spaces and the complexities involved in having to move constantly in and out of the closet.

In order to understand the conversations that took place, I use Miller's (1988) concept of 'the closet'. Miller (1988 in Hekanaho 2007) calls the closet the 'open secret', where:

The open secret defines the boundary between public and private, thus constituting the idea of homosexuality as an alternative "impossible" to think and express (Hekanaho 2007: 89-90).

It is a personal and metaphorical space where the invisibility of one's sexual identity can be maintained or can be brought out into the public sphere through discursive and performative practices. Because sexuality is an invisible difference (Butler 2006), it is only through gendered readings of identity performance and outright declaration that sexualities can be made publicly visible. Thereafter, I consider each of the three conversations that students prompted, in order to understand the implications of my pedagogical decision not to declare my sexuality. Such a decision can be argued as a way for me to hide my identity, or shame (Sears and Williams 1997), while other arguments might suggest I suffer victimisation due to an oppressive context and that I choose to participate in that (Allen 1995; Silin 1999).

Contrary to these positions, I argue that such notions about the closet and coming out need to be reconsidered. I therefore incorporate Miller's (1988) notion of the open secret with my own critical reflexivity on the conversations with students. 
Taking a reflective stance has allowed for a critical engagement with my own position in relation teacher identity and the closet (Elliston 2005; Khayatt 1999).

I therefore aim to consider issues related to the closet, coming out and teacher identity by unpacking some of the literature in this field. Specifically, I use Miller's (1988) concept of 'the open secret' as framework for understanding the negotiation of private/public identities, as well as present a selection of arguments about the role of coming out and teacher identity. I use these arguments to put forth my own position which regards the closet as a fluid and dynamic space with a myriad of possible functions, and I state the need to see decisions about coming out as being situated in circumstance (socially, culturally, politically, historically and so forth). That is, I urge that the closet be reconsidered as a space beyond struggle and victimisation exclusively, and to include possibilities for becoming a constructive space for identity formation and social negotiation. A critical reflection of my choice to not come out in my own classroom provides an illustration of how I negotiated private/public identities by rethinking the role of my own closet space.

I therefore present my argument, and the data that follows, with the following research questions in mind:

Firstly, how do pre-service teachers (students) doing a critical literacy course that I teach, on issues related to sex, gender and sexuality, read my own teacher identity?

Secondly, given my pedagogical decision NOT to come-out, how do these pre-service teachers respond to my role as teacher/lecturer?

Finally, how do these students' responses relate to the literature and arguments about the closet and coming out?

\section{“THE OPEN SECRET"}

Often "the closet" in much contemporary literature has...come to represent a barrier that needs to be broken through' (Tucker 2009: 9). But, this can be contested. If the closet is conceived of as a barrier, is it not maintained that non-heterosexual identities are abnormal or deviant? That is, by coming out of the closet and declaring one's sexual identity as being lesbian, gay or bisexual or gender identity as intersexed or transgendered, that person reinforces their identity as Other (Tucker 2009), and therefore different from an established heterosexual norm. However, this is not to say that difference cannot also function to empower marginalised groups (Janks 2010; 
Allen 1995). Stepping out of the closet and declaring one's sexual identity outright could also function to make that identity visible, publicly and politically. This may be particularly true in circumstances where 'a coming out represents the end of inauthenticity and self-alienation for the individual and the wider community' (Tucker 2009: 9).

Therefore, the decision to either remain in or come out of the closet is one about risk and safety. If remaining in the closet means actively silencing one's own identity, then there are risks of personal trauma and self-erasure. But, there is safety in this decision too. From Hammond's (2015) blog, it is easy to see that in many contexts coming out as LGBTI means making oneself vulnerable to various forms of violence. LGBTI people are open to verbal and physical abuse, institutional and social exclusion and perhaps even more dire situations.

Allen (1995), a lesbian feminist teacher, argues otherwise. She states that 'coming out is necessary to correct the assumption that everyone is heterosexual and there is only one right way to be' (Allen 1995: 138). This may be true in view of the hegemonic status that heterosexuality occupies in societies across the world, but would it be possible to read NOT coming out as a political act of normalising nonheterosexual identities? It is important to note that I do not advocate one way or the other. In each decision there are consequences and social effects. Rather, I argue that a deep consideration needs to be taken in relation to how one uses the closet in constructive ways - for both personal and political gains. For teachers, this is a particularly contentious issue. Largely, LGBTI people represent the contentious relationship between private and public (teacher) identities (Russ, Simonds and Hunt 2002; Msibi 2012).

Despite South Africa's progressive Constitution (1996) and the history of antihomophobia, anti-transphobia and even current work on heterosexism (Gevisser and Cameron 1994; Richardson 2004; Reddy 2009; Msibi 2012; Francis 2012; Bhana 2014; Schilt and Westbrook 2009), coming out can still be seen as a risky decision to make. Talking about sexual diversity in contemporary South Africa is still controversial, especially in the face of persistent separatist discourses that have been carried from apartheid.

This means that our private/public spaces, and the ways of being that we deem allowable in each, need to be constantly negotiated. This is especially true for those who inhabit identities that are in conflict with the dominant ideologies of public spaces: 
From LGBTI identities, to those in interracial or even inter-generational relationships. The sometimes jarring relationship between our personal, private identities and the performance required from us in public forums has a significant effect on how we understand subjectivity. It thus becomes useful to think about these spaces in relation to Miller's (1988) 'open secret'.

With the words 'But Officer...' Miller (1988: vii) introduces his work on literary theory and subjectivity, and their relationship to power in The Novel and the Police. Although Miller's main argument is framed around the policing power of novels, and the ways of being that they represent, his understanding of private/public spaces and identity is also applicable to the negotiation of diverse sexual identities in everyday spaces.

In order to do this, Miller (1988) draws on Foucault's notion of 'discipline' and its three underpinning components: surveillance, the regime of the norm and the technologies of self and sexuality. Firstly, surveillance refers to the often unnoticeable or taken-for-granted ways in which identity is monitored and policed. It is conceived of as 'an ideal of unseen but all-seeing surveillance, which, though partly realized in several, often interconnected institutions, is identified with none' (Miller 1988: viii). This means that, for example, while schools are significant and powerful institutions for socialisation, its role in perpetuating problematic norms through the everyday monitoring and policing of learners is often underestimated. Even problematic practices at schools are justified if they are considered to contribute to the production of a proper, civilised and well-rounded adults. Furthermore, teachers often forget the social and ontological impact that their everyday, commonsensical actions have on learners' understanding of the world (Bhana et al. 2009; Dixon 2001; Allen 1995). Even the texts (and textbooks) that are used might have very real effects on what ideals and values teachers and learners regard as permissible and impermissible (Govender 2011).

Secondly, surveillance functions to maintain and reproduce particular social norms. That is, regimes of norms, where 'normalising perceptions, prescriptions, and sanctions are diffused in discourses and practices throughout the social fabric' (Miller 1988: viii), are reproduced and maintained through repetitive actions. It is through repetition that norms become established and entrenched, forming practices and perceptions that seem natural (Butler 1993). Such regimes seem unquestionable because, over time, they become common sense and it becomes almost impossible to 
imagine a world beyond these regimes. The most powerful are those norms that pass undetected: From toilet signs that represent normative binaries of male and female sexed identities, to phrases like 'that's so gay' that reproduce the understanding that homosexuality is a condition to overcome. Such norms maintain the discourses of heteronormativity and patriarchy. Under such regimes, it can be easy to see why coming out might be a requirement for naming social nonconformists, and why 'nonconformists' might want to use processes of coming out to regain their sense of social power and agency.

Thirdly, Miller (1988: viii) discusses the 'various technologies of the self and its sexuality'. Here, it becomes possible to understand that the private subjectivities that we experience, and the ways of being that they entail, can influence the public sphere. The secrets of our private identities, like sexual identity, become forces for either becoming empowered or subordinated in the public sphere (Hekanaho 2007). Despite sexuality being an invisible difference, how we identify, or how we are perceived due to our gendered performance, may have significant effects on our experiences within the public sphere. In this regard, the closet can be thought of as a personal safe haven, or a place to hide nonconforming identities.

Let us explore these three concepts through a scenario: When Simon Nkoli ${ }^{1}$ (1994) came out as gay to his prison-mates and anti-apartheid comrades in the mid1980s, he defied the hegemonic definitions of 'black', 'male' and 'activist' in relation to masculinity. While imprisoned and awaiting trial for alleged involvement in the Delmas Treason, his fellow prison-mates began to use the separatist language of the time to distance themselves from Nkoli:

The arguments against me were that homosexuality was not African; that we cannot accept to be led by a gay person; and that I had been dishonest by hiding this vital information (Nkoli 1994: 253).

This fragmentation maintained the hegemonic masculinity of that time: that homosexuality is not African, but an imperialistic European thing brought to Africa with colonialism - a by-product of racial and cultural oppression. Such uses of language reflect the regime of norms at play during apartheid in South Africa. But, this also meant that Nkoli's sexuality was not just a defiance against normative sexual order, but also against African racial and cultural identity. 
The fact that even Nkoli's prison-mates, who followed him as part of an antiapartheid movement, felt betrayed by his 'secret' sexual identity shows the impact that naming one's sexual identity in a public space can have. That heterosexuality is not the focus of such a policing gaze indicates the paradox of an open secret (Miller 1988). However, some secrets are more shocking than others. Nkoli's relationship with a white man suddenly compounded his abuse:

"Why do you like fucking white men?" he [a policeman involved with torture and interrogation at John Vorster Square] asked. "What have they done to you? Why don't you have sex with your own people?" (Nkoli 1994: 254).

Not only did Nkoli (1994) have to come out as gay, but also as a member of an interracial relationship. This was a double-edged open secret that needed to be negotiated in order for Nkoli's activist work to have an impact on both racial and sexual policing in the apartheid era. In this particular case, the closet is associated with dishonesty: dishonesty in relation to sexual identity, where heterosexuality has been betrayed; and dishonesty in relation to race, where Nkoli's relationship with a White man is understood as a betrayal against 'his own kind'.

The dominant discourse of the apartheid era was that of separatism: From the more apparent and widely known discrimination and oppression of racial/ethnic, cultural and linguistic difference, to the subtler but no less oppressive policing of gender and sexuality. Ideas of how to do race, culture, gender and sexuality were defined in the big-P politics of legislation down to the little-p politics (Janks, 2010) of everyday life amongst South African citizens (Retief 1994; Gevisser and Cameron 1994; Tucker 2009; Bhana et al. 2007). Nkoli himself was policed through linguistic pejoratives. By coming out Nkoli tried to negotiate his own private/public spaces in order to address social inequalities. That the discourses of apartheid still persist today indicates the farreaching effects of any separatist ideology.

It is also important to note that the instruments of power that Miller (1988) discusses can be related to the surveillance and policing of gendered performance. Policing, in this regard, functions to maintain the hegemonic gender orders of particular contexts (Connell 1995; Epstein and Johnson 1998; Msibi 2011). In normative, everyday ways, hegemonic gender orders are visible. Billboards, textbooks, magazines, news reports, and so many other media reinforce the binaries of male- 
female, masculine-feminine and heterosexual-homosexual, overlooking the diversity within each of these categories. Moreover, the repetition of such representations perpetuates normative assumptions and conflations that male femininity equals homosexuality; that heterosexuality is unquestionably normal; or that intersexed and transgendered identities are unnatural.

The ideologies behind persistent and problematic representations that naturalise the normative and easy conflations between sex, gender and sexuality need to be rectified. It becomes vital to understand that 'there are no direct expressive or causal lines between sex, gender presentation, sexual practice, fantasy and sexuality' (Butler 1993: 315), despite normative gendered representations that maintain that sex gives rise to gender and that gender marks sexual identity. Heteronormative and patriarchal ideologies not only enable a particular way of seeing the world, but also influence the kinds of futures that can be imagined. It becomes difficult to see beyond current, naturalised ideologies to imagine and construct a different, more just future.

There were a range of participants in Simon Nkoli's (1994) example: From his prison-mates, to the police force, to the myriad of institutions that Nkoli would have had to negotiate being a black South African during apartheid. Similarly, our own personal identities are negotiated differently according to the different social, private and public, spaces that we inhabit. Our subjectivities can be performed and understood in a range of ways, depending on the ideological structures at work and the positions we occupy within those structures.

\section{IN AND OUT OF THE CLOSET}

In much of the literature by or about LGBTI teachers, two main ideas about the closet and coming out stand out. Firstly, the closet is seen as having a closed door thus being associated with 'hiding', 'fear' and 'stigma' and therefore is used to safe guard oneself against an oppressive and sometimes violent heterosexist context. The person who lives a 'closeted' life thus lives 'without disclosing their sexual orientation or gender identity' (Rasmussen 2004: 144). Only nonconforming identities are closeted, and are thus seen to be self-marginalising because 'the act of not coming out may be read as an abdication of responsibility, or, the act of somebody who is disempowered or somehow ashamed of their inherent gayness (Rasmussen 2004: 146). 
Secondly, and contrary to the first main way of thinking about the closet, the public declaration of one's sexual identity is associated with an open-door closet. In this metaphor, an out person 'relinquish[es] the safety that the assumption of heterosexuality confers on people who do not disclose their sexual orientation' (Freedman 1990 in Allen 1995: 136). That is, the LGBTI-identifying person is said to have freed themselves, publicly and politically, from the tyranny of compulsory heterosexuality (Rich 1993). Such a person declares their sexual identity in order to make their difference apparent - an act that benefits both the individual that has come out and their wider community (Bridgewater 1997). The open closet is thus associated with notions of valour and honesty, contrary to the notions of fear and falsity behind a closed closet door.

I have designed the following diagrams to illustrate and summarise these metaphors and how they have been constructed in the literature:

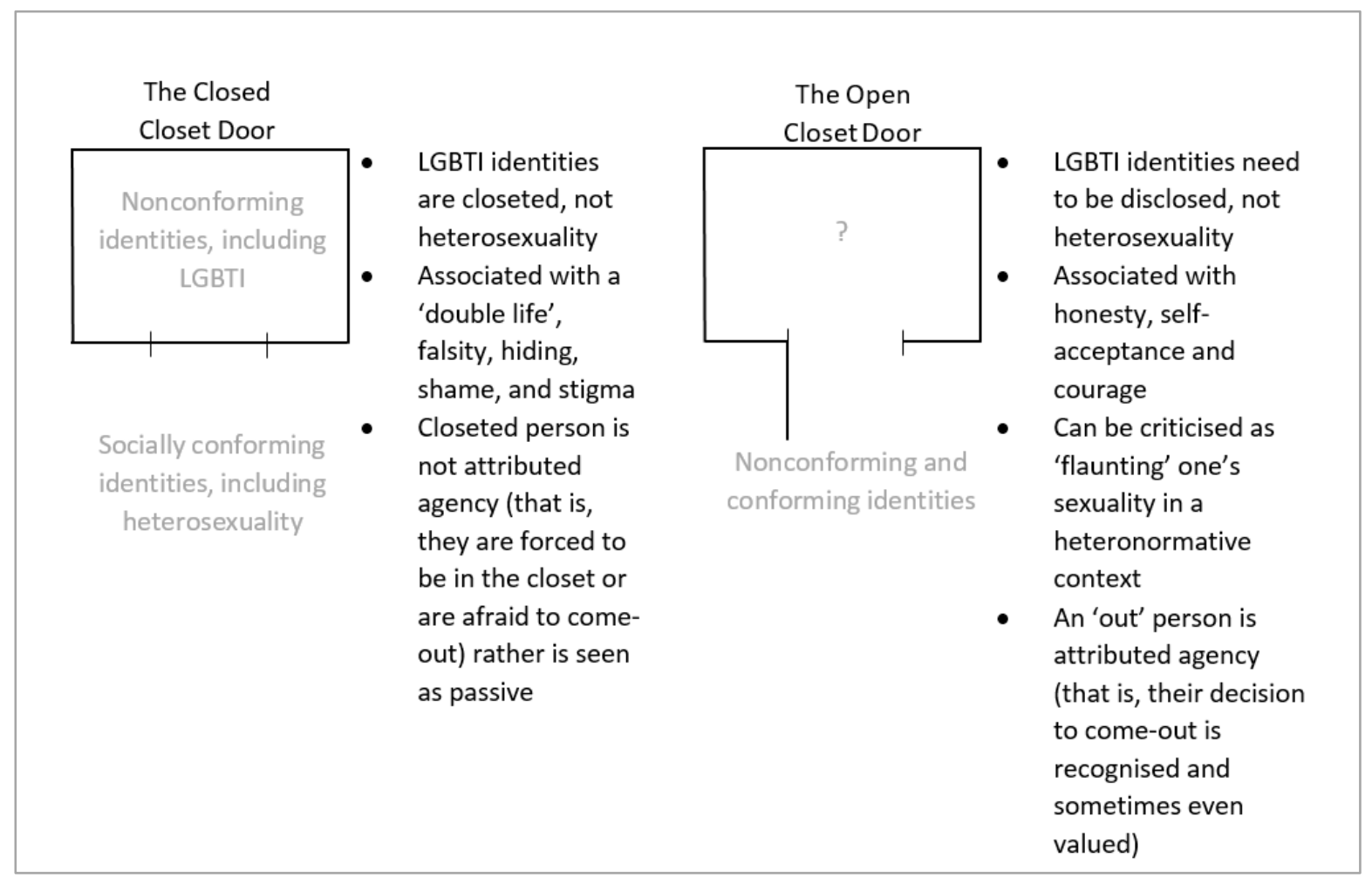

[Figure 2.1 - the closet binary]

The above descriptions of the closet produce the common binary of open/closed and in/out. Each position is justified, legitimated or stigmatised using a basic either/or argument: That is, you are either courageous or not; defying oppression or contributing toward it (Allan 1995; Rasmussen 2004; Seidman, Meeks and Traschen 
1999; Gage, Richards and Wilmot 2002; Hattingh 2005; Silin 1999). Such an essentialism of the closet negates the diverse experiences of LGBTI-identifying people across geography, history, culture/religion/tradition, language, class, race, age, occupation, and so on (Hammond 2015). It also reduces the category 'nonconforming' to sexuality and gender, thus overlooking the possibilities of coming out as one of a range of other invisible differences, including belief structure, linguistic profile, ideological position, political position, bias, or competency. In many ways, people pull their invisible differences out of their closets and risk exposing their vulnerability. What it means to be vulnerable, and the consequences of vulnerability, depends on sociocultural context in time. In the case of LGBTI-identifying people, the consequences of bringing a sexual identity out of the closet could result in anything from acceptance and normalisation to emotional and physical violence (Hammond 2015).

The range of possible reactions to coming out as LGBTI suggests that an essentialised binary of an open versus closed closet cannot suffice to deal with diverse experiences. Because LGBTI experiences can differ drastically from context to context, it becomes important to note that:

\footnotetext{
the [conventional] narrative of coming out of the closet create[s] divisions between individuals who are 'in' and 'out' of the closet. The former are stigmatized as living false, unhappy lives and are pressured to be public without considering that the calculus of benefits and costs vary considerably depending on how individuals are socially positioned (Seidman et al. 1999: 10).
}

I therefore argue the need to reconsider the closet as fluid and dynamic, and therefore any decision to come out should consider context and circumstance: 
The Ajar

Closet Door

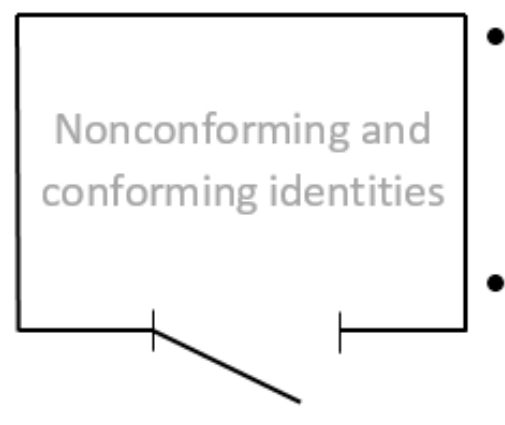

A range of conforming and nonconforming identities can be closeted or disclosed according to context and risk/safety Identity is conceptualised as a constant negotiation between public/private spaces, thus attributing agency to the person

Nonconforming and who sees coming-out as a measured decision that takes into consideration context, risk and personal well-being

[Figure 2.2 - The ajar closet door]

It is therefore important to note that the closet can be used and understood in different ways for different situations, and that the methods and reasons for coming out should also be considered as situated in time, place and circumstance (Seidman et al. 1999). That is, 'people's ability to continuously negotiate their identity is necessarily mediated by varying circulations of power relating to age, family background, economic position, and race' (Rasmussen 2004: 147) amongst others. Figure 2.2 illustrates how both conforming and nonconforming identities can be placed inside and outside of the closet, depending on social circumstance. Moving between and across private/public identities means honing in on one's agency to determine the risk factors involved with making decisions about coming out. The closet thus becomes a practice of negotiation rather than a fixed position that 'constructs gay individuals as suffering a common fate in a society organized around normative heterosexuality [and] making homosexuals into unjust social victims' (Seidman et al. 1999: 9-10).

I also propose that the closet could therefore also act as a way of resisting normative heterosexist and patriarchal ideologies. In this sense, "by assuming instead that [others] are aware of my sexual orientation, it does not focus menacing attention on itself but remains a natural part of the conversation and continues to come up 
whenever relevant' (Khayatt 1999: 10), the closet does not function as a space for hiding one's shame. Rather, the closet becomes a storage space for invisible differences. The disclosure of any these identities can be measured against the situation, where context, risk and motivation help determine the need to come out or not. In some cases, nondisclosure may be due to the risk of violence, while in other cases it may be due to the lack of relevance to the situation. There is a spectrum of reasons that may warrant, and indeed, require coming out, but there is also a spectrum of reasons not to. And, while there are certainly powerful ways of coming out that work to help deconstruct heterosexism and patriarchal discourses (Allen 1995; de Beauvoir 1993), there may also be significant value and power in using the closet to normalise LGBTI identities.

\section{METHODOLOGY}

This article uses my own reflections from teaching a critical literacy course at a university in Johannesburg, South Africa, for the Bachelor of Education (B.Ed.) in English degree. This data set comes from a larger qualitative research project entitled, Negotiating the Gendered Representations of Sexualities through Critical Literacy (Govender 2015) where I developed and implemented a workbook that uses a critical literacy approach to engage pre-service teachers with issues related to sex, gender, sexuality and the conflations between them. This larger project was interested in how pre-service teachers would respond to sensitive topics, such as those related to sex, gender and sexuality, using a critical literacy orientation. Both the workbook and the course were thus divided into 4 main topics for discussion: 1) Language, 2) Policing and Subversion, 3) (Re)Design, and 4) Social Impact (see Govender 2015 for a detailed explanation of the workbook, the course and other course materials). The course was compulsory for students studying English as a major or sub-major and required that students engage in critical literacy practice to confront issues of sex, gender, sexuality and the conflations between them.

Despite the course being compulsory, the students who participated in the research project did so voluntarily. Students were notified of the ethical considerations of the project through detailed information and consent forms, which outlined the main principles of ethical qualitative research (Cohen, Manion and Morrison 2000): 1) Participation was voluntary throughout the study; 2) All participants' confidentiality has been maintained through the use of pseudonyms; and 3) No participant was required 
to identify their own sexual or gender identity at any point. Any declaration, in any form, was done so voluntarily by the participant. Counselling services were available should any participant have required it.

In this article, I draw on my reflections on the critical literacy course, written after each lecture session. I use these notes to present a critical reflection (Elliston 2005; Khayatt 1999; Fook, White and Gardner 2006) of three conversations, elicited by students, that are related to the closet, coming out and teacher identity as a result of the course content. The practice of critical reflexivity in educational research provides a method for engaging with the subjectivities of teachers and researchers in educational settings. Furthermore, it allows for 'critical insights into the relationships between sexuality and cultural politics' (Elliston 2005: 21) in education from a position of honesty and awareness.

In the sections that follow, I describe each conversation and then unpack them by drawing on Miller's (1988) notion of the open-secret, as well as various arguments on the relationship and politics of teacher identity and the closet. I consider each conversation in relation to the main arguments encapsulated in Figures 2.1 and 2.2 of this article.

\section{FINDINGS}

When it came to teaching the course, I made the decision to step into the classroom without declaring my sexual orientation to the students. As a gay Indian male in South Africa, I did not make this decision out of fear of marginalisation or reproach, although these are legitimate fears, but from the intention to construct sexual diversity as normative (Khayatt 1999). That is, it may not even occur to a heterosexual teacher to identify as a heterosexual when teaching university students or school-going learners. It is an unnecessary identity trait to declare in the classroom. In this sense, it is not about staying in the closet (Tucker 2009) but about giving a gay identity normative status in a way that might also be adopted by other LGBTI teachers. Therefore, while this position may be contestable, it has also had its affordances for understanding my role as a teacher. In this section I discuss three conversations that took place because of my not coming out, which was highlighted by the course content. In each conversation, it becomes apparent that students read my teacher identity in gendered ways. Such readings have implications for how teachers can think about their own identities in relation to private/public spaces. It is also important to note that 
at certain points in Conversations 1 and 2, I did eventually come out, while in Conversation 3 I did not.

\section{Conversation 1}

It was after the class on Gender Violations that a young female student, 'Interested' (pseudonym), approached me. While the other students were leaving, Interested walked up to the podium where I stood. She thanked me and briefly stated that it was helping her and her friends to understand sexual and gender diversity. However, after I responded with gratitude, Interested asked me if I was gay. I paused; I smiled and proceeded to interrogate the reasons behind her question: Why would you like to know? Would it make a difference? What makes you think I might be gay? She answered briefly, but courteously and confidently, that it did not matter within the classroom context. Despite that 'it did not matter', it is still important to note that Interested persisted in questioning my sexual identity.

After I had answered her question in the affirmative, she then proceeded to make the following analysis. Note that quotes come from my own reflections after each lecture and thus may not be word-for-word what Interested said. However, these recordings were taken shortly after each class in the attempt to maximise the accuracy of my memory:

You remind me of my brother. He is gay, and you both act the same. You know, the hand movements and stuff (extract from RJB-L4:24).

It is clear, then, that Interested had been reading how I had been performing my gendered identity (Butler 1993 and 2006; Connell 1995; Luyt 2012) - alongside my performances as Indian, South African, a teacher and a researcher. She then read my less-than-hegemonic performance of masculinity as an indicator of sexual orientation. My 'hand movements and stuff' were understood as markers of my sexuality.

From literature on gender and sexuality, it is easy to identify Interested's reading of my gender performance as within heteronormative bounds. That is, gender performance (as explained by Butler 2006) was falsely read as a representation of sexual identity. Gender and sexuality were conflated to form the fallacy that nonheterosexual orientations are identifiable through non-hegemonic gender 
performances. And so, because the way I move my hands falls outside of the criteria of hegemonic masculinity, it might be safe to assume that I am gay.

However, while I agree with Butler (1993), I also cannot deny that I am still gay and that to some extent my behaviour stems from that identity, amongst others. That is, because of my understanding of gender performance and social constructions of masculinities, I am able to feel less than most the need to police myself and abide by the rules of hegemonic order. Instead, through indifference I am able to resist and perform identity outside of that order.

Despite the course's attempt to disrupt gender-sexuality conflations in representation, Interested's need to try and identify my sexual orientation becomes an interesting point. It is interesting because it used my sexual orientation, which I did not deny, as a rationalisation for the gendered performance she was reading. It also allowed her to use my gendered performance to rationalise my sexuality. However, it can also bring one's investment into question: who can be interested in issues of sexual and gender diversity? My next encounter with a young female student beckons this question of investment.

\section{Conversation 2}

I arrived at the lecture venue early one day to find a student, Conflicted (pseudonym), already seated in the front row. We greeted each other, but did not take much notice, as I settled by bags and began to set up for the presentation. Conflicted eventually walked up to the podium before the class:

Can I ask you something? ... Are you gay? (extract from RJA-L5:04).

As with Interested, I proceeded to interrogate her reasons for asking me this question. However, while Conflicted reiterated that my being gay would not make a difference to my role as the teacher, she did come to an interesting conclusion:

Oh, I was wondering why a straight man would want to teach a course like this (extract from RJA-L5:04).

Unfortunately, I did not have the opportunity to ask her more about why she said this. It does seem to raise the concern of who is allowed to be invested in certain topics. Should only Black scholars research and teach African studies? Should only women 
be interested in feminism? Would it be inappropriate to have a White male involved in post-colonial studies? That is, am I only invested in teaching and researching about sexual diversity because I am gay? And, what does this mean for the range of identities that I include in the course?

While I must admit that my own identities as gay and as male have undoubtedly influenced the equity of time spent dealing with the representation of different identities in class, I find it problematic to think that it is only because I am gay that I am interested in issues of sexual diversity. It is not a case of the perverse leading students into perversity (Dollimore 1991 in Epstein and Johnson 1998), but the teaching of an approach that uses social justice education to deconstruct the representations that emerge from hegemonic ideologies (Msibi 2014; Francis and Msibi 2011; Johnson 2014; Bhana 2014). Surely, then, anyone working for social justice might be invested.

\section{Conversation 3}

While in the first two conversations, my lack of self-identification initiated curiosity, in the third conversation it has allowed a group of students to open up to me during an in-class group activity on drag identities ${ }^{2}$. This group of students was one that I would label as more conservative and who seemed to conflate race, culture/tradition and religion in their resistant speak on issues of sexual diversity.

During group work activities I would walk around the lecture venue to assist with or contribute to students' group discussions. In one case, a member of the group of more conservative students raised his hand to call me. They were concerned with whether they would be able to teach about topics related to sexual and gender diversity when they themselves did not believe that it was right. It was at this point that the conflated discourses of race, culture/tradition and religion-based morality made itself most apparent.

Firstly, the students simplified 'sexual diversity' into 'homosexuality'. They only saw heterosexuality and its binary opposite within normal/natural versus deviant/unnatural framework. Secondly, their race, culture/tradition and Christian beliefs were used in restrictive ways that prevented them from seeing LGBTI identities as worthy for the classroom. Words like 'wrong' or 'not allowed' were used to construct nonconforming sexual and gender identities, while phrases such as 'we know' and 'in Black culture' naturalised and legitimated (Thompson in Janks 1998 and 2010; 
DePalma and Francis 2014) their own positions. Altogether, their discourses suggested a tension between their own positions and the responsibilities of a teacher working under South Africa's national curriculum (DoBE 2011) and secular constitution that we had spoken about during the course.

It is reasonable to expect that such tensions between identities, beliefs and professional expectations would arise (Msibi 2014; Francis 2012), especially in a course that deals with what is still widely regarded as a controversial topic. What is most interesting to me, however, is that this group of students did not feel the need to withhold their views when speaking to me about their conflictions - they seemingly only did so during whole class discussions. This may be attributed to my own elusive sexual identity in the classroom. These students did not seem to read my gender performance or interrogate my investment in sexual diversity. Instead, I assume, they saw me as somewhat neutral or as existing outside of the identities we were dealing with in class. Had any of these students been aware of my gay identity, I do not think that they would have so freely discussed the tensions they were feeling, nor would they have used such explicit heterosexism to describe that tension.

My pedagogical decision not to declare my identity has afforded me the experience of these three conversations. For it is within these conversations that the need to categorise people becomes apparent, especially when those people are read as ambiguous or in some way deviant from hegemonic order. On one hand, had I performed maleness 'correctly', I do not think anyone would have questioned my sexuality and there would be no need to come out. And yet, on another hand, these moments illustrate how knowing, or assuming, someone's sexual identity might influence what it means to interact with them (Russ et al. 2002; Bhana et al. 2007 and 2009).

How we police our identities and behaviours - our words, our actions, our gestures and our resistances - can be determined by our context and social relations. Both the students who read my gender performance and the group who opened up to me in class evaluated their own possible risks before engaging with me. In Conversations 1 and 2, it put me in a position where I decided to come out, while in Conversation 3 coming out was not necessary and may have even hindered students' honesty. Had I come out as gay, it is possible that the group of students would have kept silent, thus muting a valuable contribution that legitimised and gave voice to the tensions that others may have shared. 


\section{DISCUSSION OF FINDINGS}

In each of the above scenarios, students read my gender performance as well as my performance of the role of teacher. In the first two conversations, both Interested and Conflicted respectively show how they were trying to rationalise and come to terms with my identity. On one hand, Interested tried to determine what my sexual identity was by noting my gender performance and inadvertently conflated gender and sexuality. That is, her reading of my identity was grounded in the conventional, but mistaken (Butler 1993 and 2006), construction that gender naturally signifies and marks sexuality. This resonates with traditional cis-gender models of sex, gender and sexuality (Schilt and Westbrook 2009; Schilt and Windsor 2014) that see gender as a natural result of biological sex. On the other hand, 'Conflicted' tried to use her reading of my gender performance, and thus my sexual identity, to rationalise my investment in teaching about issues related to sex, gender and sexual diversity (McCarl Nielson, Walden and Kunkel 2000).

Importantly, however, is that the very question that these students asked - 'Are you gay?' - required me to confront my own understanding of how to negotiate private/public spaces (Miller 1988). Ultimately, these students attempted to draw my private identity into a public space, and by answering their question, I chose to come out. However, is asking 'Are you gay?' permissible in the first place? If it draws out one's private identities into public spaces, forcefully or subtly, the question reinforces that those invisible, private differences indeed matter, even in situations where they do not. In this way, asking someone to come out also represents a negotiation of power where:

\footnotetext{
It also helps preserve the very models of social and psychological centering that, as though they had entranced even the activity of demystifying them, are tirelessly rehearsed within it (Miller 1988: xii).
}

Despite every attempt that the critical literacy course made to reveal the social construction of gender as performance (Butler 2006), these students still used the course to maintain problematic conflations between gender and sexuality, however unintentional. 
Given the context within which these students chose to approach me, and the fact that they perceived my sexual identity as open for interrogation, it is important to note that I did not hesitate to answer. This is significant in how it constructs my own position in relation to the boundaries between private and public. That is, while I made a clear pedagogical decision not to come out to my class, I also was not ashamed of my invisible identities - be it sexual, gendered, ethical, occupational, ethnic, or other. My identities thus move in and out of the closet, in and out of secrecy in relation to my context and social circumstance. Difference and sameness, then, are constantly negotiated in social and ideological context. Khayatt (1999) explores this idea in her own writing, and it thus becomes useful to quote her work at length:

\footnotetext{
I wonder who benefits and who loses and who remains indifferent when we come out by using a declarative statement. How do we ascertain the effect that our words will have? In refraining from telling my parents in Egypt about my sexuality, I was not refusing to interrupt their heterosexual assumptions, nor was I hoarding a secret. I was considering the cultural context in which I would make my announcement. I considered how my parents would feel and what I stood to gain from telling them, and I faced the dilemma of wanting to protect them from knowing but needing for them to know (Khayatt 1999: 111).
}

She goes on to relate this to her experiences and expectations with students in the classroom:

\begin{abstract}
The subject of my life is no longer an issue with my family. They know about me and in fact knew long before I told them ... My way of telling them took them and their context into consideration, and a declarative statement would have been irrelevant. The process was thoughtful and caring, and I feel that I would owe it to my students, should I ever need to have that conversation with any of them (Khayatt 1999: 111).
\end{abstract}

Khayatt's (1999) understanding of coming out is one that I share. Should need or relevance arise, my sexual identity can be pulled from the closet and out into the public sphere. However, more often than not, my sexual identity does not contribute to students' education and can be left alone.

In the third scenario, my pedagogical decision not to come out seemingly opened up classroom space for students to respond to the issues at hand with honesty. While it is entirely possible that these students might have still withheld some of their 
concerns about the course content from me because of my roles as teacher and researcher, it is also interesting to note how readily their own heterosexist discourses were brought out of the closet and into public discussion, whether based on prejudice or ignorance (Francis 2012; Bhana 2014).

Because processes of coming out represent a negotiation of power relations, it becomes vital for teachers to think carefully about the roles they choose to play in relation to sex, gender and sexuality, as well as issues related to reproducing, maintaining and resisting normative gender hegemonies. Teachers' identities are, more likely than not, being read by students all the time. The question, then, is whether or not teachers can reflect on these readings in order to understand how students use course content to rationalise the world. In classrooms, teachers should not be void of interrogation. But, the negotiation of private and public spaces needs to be done carefully and thoughtfully (Khayatt 1999; Seidman et al. 1999; Rasmussen 2004). In my conversations with students, questions could still be raised about whether or not my intention to represent my own 'non-conforming' sexual identity as normative actually worked. Further questions could be asked about the actual effect of my responses when students asked me about my sexual identity. There are no clear-cut answers, but a critical reflection on the interaction between teachers and their students might help to unravel how scholars come to terms with new content and theories, new ways of seeing the world, and the pedagogy employed to deal with these.

\section{CONCLUSION}

In this article, I have outlined some of the arguments related to whether or not and how teachers ought to come out of the closet in classrooms, specifically focussing on Miller's (1988) notion of the open secret. I have also put forth my argument that any decision to come out needs to consider context, risk and circumstance. This is evidenced by arguments and analyses by Rasmussen (2004), Khayatt (1999), and Seidman et al. (1999), as well as further illustrated by Hammond's (2015) blog on the variety of lived circumstances and risks that LGBTI people live in across the globe.

In order to explore my position on coming out, the closet and teacher identity, I have also reflected on three conversations instigated by B.Ed. students attending a course on critical literacy. The conversations illustrated how these students engaged with my pedagogical decision not to come out. I use these conversations to explore the fluidity of the closet, and to undermine the common associations between the closet 
and shame, silence and fear. Rather, I engage with the ways in which not coming out played a role in students' readings of my gendered identity performance in class. It stands, then, that the closet, as well as acts of coming out, can perform various functions across contexts and circumstances. I have been lucky to live within relatively unoppressive contexts, yet I cannot ignore the possible risks of violence that coming out might result in for other teachers in other, more oppressive circumstances.

\section{NOTES}

1 Simon Nkoli was a human rights activist who fought not only against racial segregation and discrimination but also against the discrimination of gay and lesbian people during the time of South Africa's apartheid era. Writing about and by Nkoli can be found in the seminal publication Defiant Desire, edited by Mark Gevisser and Edwin Cameron (1994).

2 The lecture on drag identities involved exploring a how Pieter Dirk Uys (a popular South African comedian), Eddie Izzard (a British comedian) and photographer Leland Bobbè represent drag identities as personal gender performance and/or theatrical performance.

\section{REFERENCES}

Allen, K. R. 1995. Opening the Classroom Closet: Sexual Orientation and SelfDisclosure. Family Relations 44(2): 136-141.

Bhana, D., Morrell, R., Hearn, J. \& Moletsane, R. 2007. Power and Identity: An Introduction to Sexualities in Southern Africa. Sexualities 10(2): 131-139.

Bhana, D., de Lange, N. \& Mitchell, C. 2009. Male Teachers Talk about Gender Violence: "Zulu men demand respect". Educational Review 61(1): 49-62.

Bhana, D. 2012. Understanding and Addressing Homophobia in Schools: A View of Teachers. South African Journal of Education 32: 307-318.

Bhana, D. 2014. Ruled by Hetero-norms? Raising some Moral Questions for Teachers in South Africa. Journal of Moral Education 43(3): 362-376.

Bridgewater, D. 1997. Effective Coming Out: Self-Disclosure Strategies to Reduce Sexual Identity Bias. In J. T. Sears and W. L. Williams (eds.) Overcoming Heterosexism and Homophobia: Strategies that Work. New York: Columbia University Press.

Butler, J. 1993. Imitation and Gender Insubordination. In H. Abelove, M. Aina Barale \& D. M. Halperin (eds.) The Lesbian and Gay Studies Reader. New York and London: Routledge.

Butler, J. 2006. Gender Trouble. New York: Routledge Classics. 
Cohen, L., Manion, L. \& Morrison, K. 2000. Research Methods in Education, fifth edition. London and New York: Routledge Falmer.

de Beauvoir, S. 1993. From Maturity to Old Age. In A. Minas (ed.) Gender Basics: Feminist Perspectives on Women and Men. Belmont, CA: Wadsworth.

Department of Basic Education. 2011. Curriculum and Assessment Policy Statement: Grades 10-12, English Home Language. Pretoria and Cape Town: Department of Printing Works.

Connell, R. W. 1995. Masculinities. Australia: Allen and Unwin.

DePalma, R. \& Francis, D. 2014. Silence, Nostalgia, Violence, Poverty...: What does 'Culture' Mean for South African Sexuality Educators? Culture, Health \& Sexuality 16(5): 547-561.

Dixon, K. 2001. Literacy, Power, and the Schooled Body: Learning in Time and Space. New York: Routledge.

Elliston, D. 2005. Critical Reflexivity and Sexuality Studies in Anthropology: Siting Sexuality in Research, Theory, Ethnography, and Pedagogy. Reviews in Anthropology 34: 21-47.

Epstein, D. \& Johnson, R. 1998. Schooling Sexualities. Buckingham and Philadelphia: Open University Press.

Fook, J., White, S. \& Gardener, F. 2006. Critical Reflection: A Review of Contemporary Literature and Understandings. In Critical Reflection in Health and Social Care. UK: McGraw-Hill Education.

Francis, D. A. 2012. Teacher Positioning on the Teaching of Sexual Diversity in South African Schools. Culture, Health \& Sexuality 14(6): 597-611.

Francis, D. \& Msibi, T. 2011. Teaching about Heterosexism: Challenging Homophobia in South Africa. Journal of LGBT Youth 8(2): 157-173.

Gage, S., Richards, L. \& Wilmot, H. 2002. Queer. New York: Thunder's Mouth Press. Gevisser, M. \& Cameron, E. 1994. Defiant Desire. Johannesburg: Ravan Press. Govender, N. N. 2011. Critical Literacy: Do Textbooks Practise What They Preach? English Quarterly 42(3-4): 57-82.

Govender, N. N. 2015. Negotiating the Gendered Representations of Sexualities through Critical Literacy. Unpublished Ph.D. Thesis, University of the Witwatersrand, South Africa.

Government of South Africa. 1996. The Constitution of the Republic of South Africa. Pretoria: Government Printers. 
Hammond, R. 2015. Where Love is Illegal. Retrieved 3/02/2015 from http://whereloveisillegal.com/

Hattingh, C. 2005. Struggles of Authenticity. In M. van Zyl and M. Steyn (eds.) Performing Queer: Shaping Sexualities 1994-2002 Volume One. Roggebaai: Kwela Books.

Hekanaho, P. L. 2007. Speaking out from the Closet? The queer reader's position of knowledge and the works of Marguerite Yourcenar: A variation on the theme of presenting a queer theoretical doctoral thesis. SQS 1(7): 89-94.

Janks, H. 1998. Reading Womanpower. Pretexts: Studies in Writing and Culture 7(2): 195-212.

Janks, H. 2010. Literacy and Power. New York: Routledge.

Johnson, B. 2014. The Need to Prepare Future Teachers to Understand and Combat Homophobia in Schools. SAJHE 28(4): 1249-1268.

Khayatt, D. 1999. Sex and Pedagogy: Performing Sexualities in the Classroom. GLQ: A Journal of Lesbian and Gay Studies 5(1): 107-113.

Luyt, R. 2012. Constructing hegemonic masculinities in South Africa: The discourse and rhetoric of heteronormativity. Gender and Language 6(1): 47-77.

McCarl Nielson, J., Walden, G. \& Kunkel, C. A. 2000. Gendered Heteronormativity: Empirical Illustrations in Everyday Life. The Sociological Quarterly 21(2): 283-296.

Miller, D. A. 1988. The Novel and the Police. London: University of California Press.

Msibi, T. 2011. The Lies We Have Been Told: On (Homo)Sexuality in Africa. Africa Today 58(1): 55-77.

Msibi, T. 2012. 'I'm used to it now': Experiences of Homophobia among Queer Youth in South African Township Schools. Gender and Education 24(5): 515-533.

Msibi, T. 2014. The Teaching of Gender and Sexuality Diversity Issues to PreService Teachers at the University of KwaZulu-Natal: Lessons from Student Exam Responses. Alternation Special Edition 12: 385-410.

Nkoli, S. 1994. Wardrobes: Coming Out as a Black Gay Activist in South Africa. In M. Gevisser and E. Cameron (eds.) Defiant Desire. Johannesburg: Ravan Press.

Rasmussen, M. L. 2004. The Problem of Coming Out. Theory into Practice 43(2): 144-150.

Reddy, V. 2009. Perverts and Sodomites: Homophobia as hate speech in Africa. Southern African Linguistics and Applied Language Studies 20(3): 163-175. 
Reddy, V. 2012. Homophobia, Human Rights and Gay and Lesbian Equality in Africa. Agenda: Empowering Women for Gender Equity 16(50): 83-87.

Retief, G. 1994. Keeping Sodom out of the Laager. In M. Gevisser and E. Cameron (eds.) Defiant Desire. Johannesburg: Ravan Press.

Rich, A. 1993. Compulsory Heterosexuality and Lesbian Existence. In H. Abelove, M. Aina Barale \& D. M. Halperin (eds.) The Lesbian and Gay Studies Reader. New York and London: Routledge.

Richardson, E. M. 2004. 'A Ripple in the Pond': Challenging Homophobia in a Teacher Education Course. Education as Change 8(1): 146-163.

Russ, T. L., Simonds, C. J. \& Hunt, S. K. 2002. Coming Out in the Classroom... An Occupational Hazard?: The Influence of Sexual Orientation on Teacher Credibility and Perceived Student Learning. Communication Education 51(3): 311-324.

Schilt, K. \& Westbrook, L. 2009. "Gender Normals," Transgender People, and the Social Maintenance of Heterosexuality. Gender \& Society 23(4): 440-464.

Schilt, K. \& Windsor, E. 2014. The Sexual Habitus of Transgender Men: Negotiating Sexuality Through Gender. Journal of Homosexuality 61: 732-748.

Sears, J. T. \& Williams, W. L. 1997. (eds.) Overcoming Heterosexism and Homophobia: Strategies that Work. Columbia University Press.

Seidman, S., Meeks, C. \& Traschen, F. 1999. Beyond the Closet? The Changing Social Meaning of Homosexuality in the United States. Sexualities 2(1): 9-34.

Silin, J. G. 1999. Teaching as a Gay Man: Pedagogical Resistance or Public Spectacle? GLQ: A Journal of Lesbian and Gay Studies 5(1): 95-106.

Tucker, A. 2009. Queer Visibilities: Space, Identity \& Interaction in Cape Town. Sussex, UK: Wiley-Blackwell. 